\title{
Inhibiting cell migration and cell invasion by silencing the transcription factor ETS-1 in human bladder cancer
}

\author{
Li Liu ${ }^{1,2,4, *}$, Yuchen Liu ${ }^{1, *}$, Xintao Zhang ${ }^{1, *}$, Mingwei Chen ${ }^{1}$, Hanwei Wu ${ }^{1}$, Muqi Lin ${ }^{1}$, \\ Yonghao Zhan ${ }^{1,4}$, Chengle Zhuang ${ }^{1,4}$, Junhao Lin ${ }^{1,4}$, Jianfa $\mathrm{Li}^{1,4}$, Wen Xu${ }^{1}$, Xing Fu ${ }^{1}$, \\ Qiaoxia Zhang ${ }^{1}$, Xiaojuan Sun ${ }^{1}$, Guoping Zhao ${ }^{1,5}$, Weiren Huang ${ }^{1,3}$ \\ ${ }^{1}$ Key Laboratory of Medical Reprogramming Technology, Shenzhen Second People's Hospital, The First Affiliated Hospital of \\ Shenzhen University, Shenzhen, China \\ ${ }^{2}$ Urology Department, Qingyuan People's Hospital, The Sixth Affiliated Hospital of Guangzhou Medical University, Qingyuan, China \\ ${ }^{3}$ Department of Urology, Peking University First Hospital, Institute of Urology, Peking University, National Urological Cancer \\ Center, Beijing, China \\ ${ }^{4}$ Shantou University Medical College, Shantou, China \\ ${ }^{5}$ Shanghai-MOST Key Laboratory of Health and Disease Genomics, Chinese National Human Genome Center at Shanghai, \\ Shanghai, China \\ *These authors contributed equally to this work
}

Correspondence to: Weiren Huang, email: pony8980@163.com

Keywords: bladder cancer, ETS-1, oncogene, cell migration, cell invasion

Received: August 21, $2015 \quad$ Accepted: January 20, 2016

Published: February 04, 2016

\section{ABSTRACT}

As one of the members of the ETS gene family, the transcription factor v-ets avian erythroblastosis virus E26 oncogene homolog 1 (ETS-1) plays key role in the regulation of physiological processes in normal cells and tumors. In this study, we aimed to investigate the relationship between the transcription factor ETS-1 and malignant phenotypes of bladder cancer. We demonstrated that ETS-1 was upregulated in human bladder cancer tissue compared to paired normal bladder tissue. In order to evaluate the functional role of ETS-1 in human bladder cancer, vectors expressing ETS-1 shRNA and ETS-1 protein were constructed in vitro and transfected into the human bladder cancer T24 and 5637 cells. Our results showed that the transcription factor ETS-1 could promote cell migration and cell invasion in human bladder cancer, without affecting cell proliferation and apoptosis. In conclusion, ETS-1 plays oncogenic roles through inducing cell migration and invasion in human bladder cancer, and it can be used as a therapeutic target for treating human bladder cancer.

\section{INTRODUCTION}

Human bladder cancer is one of the most common cancers worldwide [1]. Although methods for early diagnosis of bladder cancer and more suitable surgeries were emerged, the mortality rate has not been decreased effectively [2]. One of these important reasons is that the potential mechanisms causing cancer progress are still poorly understood. Therefore, searching novel reliable biomarkers and revealing the molecular mechanism of bladder cancer for developing effective therapy are necessary.

As the first found member of the ETS transcription factors family, the transcription factor v-ets avian erythroblastosis virus E26 oncogene homolog 1 (ETS-1) plays diverse roles in physiological and pathological processes, such as embryonic development, angiogenesis, and hematopoietic differentiation [3, 4]. Furthermore, deregulated ETS-1 also has been observed in the carcinogenesis, invasion, and progression of various tumors $[5,6,7]$. One of the potential mechanisms of ETS1 is to activate the transcription of several proteases, such as matrix metalloproteinases (MMPs) and urokinase-type plasminogen activator $[5,6,7]$. However, the functional character of ETS-1 in human bladder cancer is still unclear. Therefore, we aimed to study the expression pattern of ETS-1 and to determine its functional role in human bladder cancer. 


\section{RESULTS}

\section{ETS-1expression level was increased in bladder cancer}

The relative expression level of ETS-1 was examined using real-time $\mathrm{qPCR}$ in a total of 42 patients with bladder cancer. The ETS-1 expression fold-change (bladder cancer tissue/matched normal tissue) in most patients were greater than zero in Figure 1A. Similarly, as shown in Figure 1B, The expression levels of ETS-1 were significantly upregulated in bladder cancer tissues compared with matched normal tissues. These results manifested that ETS-1 should play oncogenic role in bladder cancer. After that, we assessed the relationship between ETS-1 expression level and clinical-pathologic characteristics in 42 patients with bladder cancer. In Table 1, the results indicated that ETS-1 expression level was associated with the depth of invasion in these patients with bladder cancer, but it has no relationship with the age, the gender and the grade. These results suggested that ETS-1overexpression may be related to bladder cancer invasion.

\section{Inhibition or activation of the expression of ETS-1 in bladder cancer}

Bladder cancer 5637, T24 and UMUC-3 cells were cultured and treated with ETS-1 shRNA or the overexpression vector. The related expression level of ETS-1 was tested by real-time qPCR at 48 hours after treatment. The data indicated that the related expression level of ETS-1 in 5637 (Figure 2A), T24 cells (Figure 2B) and UMUC-3 (Figure 2C) was observably downregulated by the specific ETS-1 shRNA. Also, the over- expression vector increased the expression level of ETS1 in 5637 (Figure 2D), T24 (Figure 2E) and UMUC-3 (Figure 2F) cells.

\section{ETS-1 promoted bladder cancer cell migration in vitro}

In order to evaluate the role of ETS-1 in regulating human bladder cancer migration, bladder cancer 5637, T24 and UMUC-3 cells were treated with ETS-1 shRNA or the over-expression vector and analyzed by the cell migration assay afterwards. Compared to the negative control group, cell migration ability was significantly inhibited by the ETS-1 shRNA in 5637 cells (Figure 3A), T24 cells (Figure 3B) and UMUC-3 cells (Figure 3C). In contrast, cell migration ability was significantly enhanced by the ETS-1over-expression vector in 5637 cells (Figure 3D), T24 cells (Figure 3E) and UMUC-3 cells (Figure 3F). These results demonstrated that ETS-1 positively facilitate the bladder cancer cell migration.

\section{ETS-1 promoted bladder cancer cell invasion in vitro}

We further investigated whether ETS-1also promotes cell invasion in bladder cancer. Here, the invasion assay was used to verify our hypothesis. As Shown in Figure 4A-4C, compared with the negative control group, the cell invasion ability was extremely suppressed in 5637 cells, T24 cells and UMUC-3 cells which were transfected with ETS-1 shRNA. As shown in Figure 4D-4F, compared with the negative control group, the cell invasion ability was extremely enhanced in 5637 cells, T24 cells and UMUC-3 cells which were treated with ETS-1 over-expression vector. These data
A

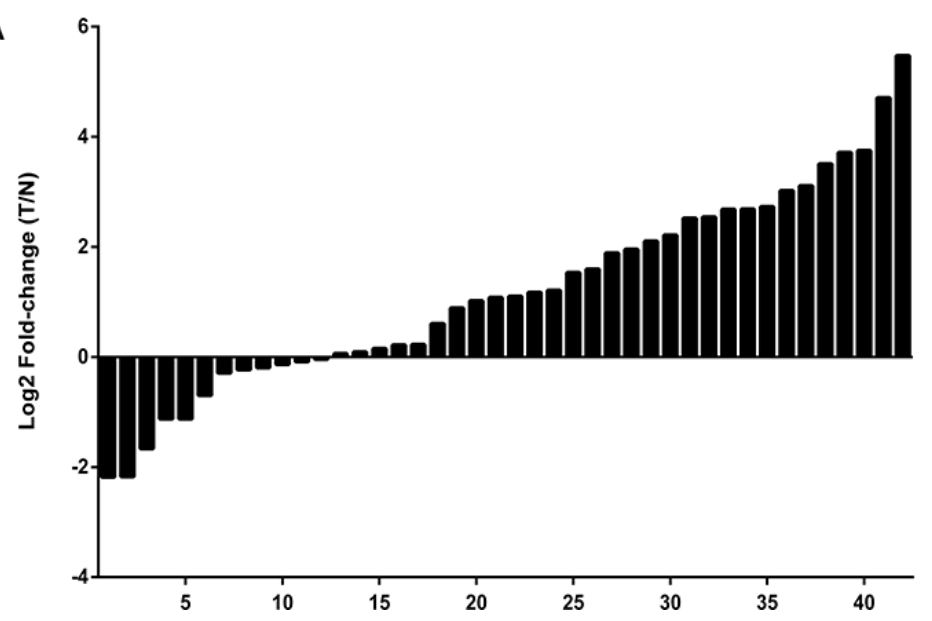

B

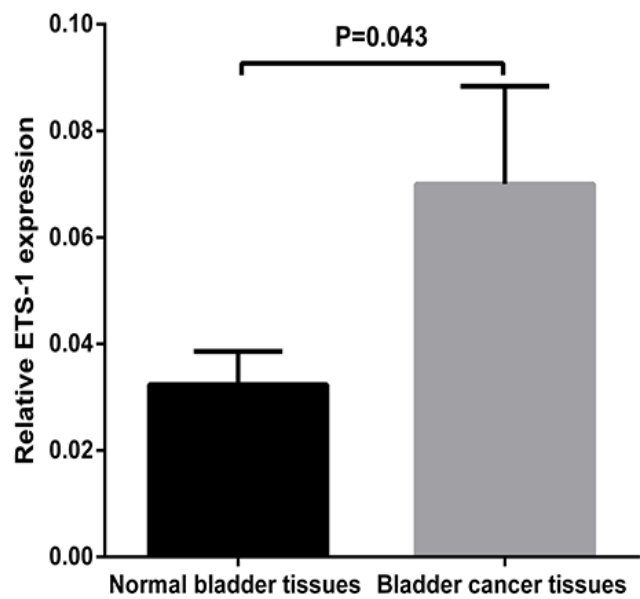

Figure 1: ETS-1expression level was increased in bladder cancer. The relative expression levels of ETS-1were detected using Real-Time qPCR in 42 bladder cancer patients. (A) The height of the columns in the chart represents the log2-transformed fold changes (bladder cancer tissue/normal bladder tissue) of ETS-1 expression in 42 patients with bladder cancer. (B) The expression levels of ETS-1 were significantly up-regulated in bladder cancer tissues compared with matched normal tissues. Data are shown as mean \pm SD. $T$ represents tumor, $N$ represents normal. 
Table 1: The relationship between ETS-1 level and clinical-pathologic characteristics in 42 patients with bladder cancer

\begin{tabular}{|c|c|c|c|c|}
\hline \multirow{2}{*}{ Variable } & \multirow{2}{*}{$\frac{n}{42}$} & \multicolumn{2}{|c|}{ ETS-1 level } & \multirow{2}{*}{$P$} \\
\hline & & low & high & \\
\hline \multicolumn{5}{|l|}{ Age } \\
\hline$<60$ & 12 & 4 & 8 & 0.957 \\
\hline$\geq 60$ & 30 & 8 & 22 & \\
\hline \multicolumn{5}{|l|}{ Gender } \\
\hline Male & 33 & 11 & 22 & 0.372 \\
\hline Female & 9 & 1 & 8 & \\
\hline \multicolumn{5}{|l|}{ Grade } \\
\hline Low & 11 & 1 & 10 & 0.202 \\
\hline High & 31 & 11 & 20 & \\
\hline \multicolumn{5}{|l|}{ Depth of invasion } \\
\hline $\mathrm{Ta}-\mathrm{T} 1$ & 12 & 0 & 12 & $0.027 *$ \\
\hline $\mathrm{T} 2-\mathrm{T} 4$ & 30 & 12 & 18 & \\
\hline
\end{tabular}

${ }^{*} P<0.05$ was considered significant. Continuous correction chi-square test was used for the statistical analyses.

A

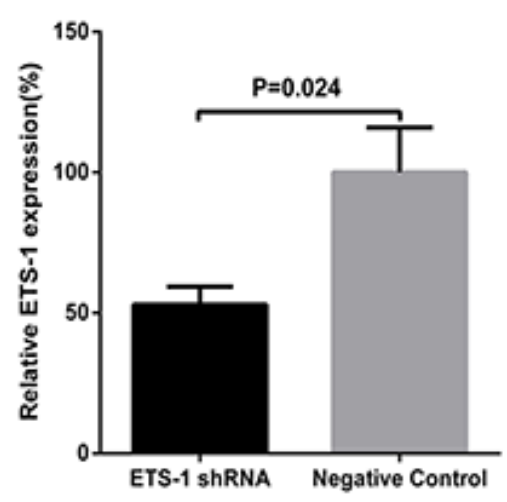

D

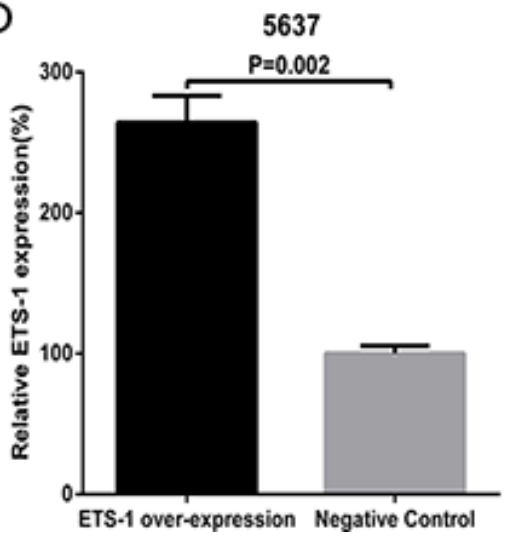

B

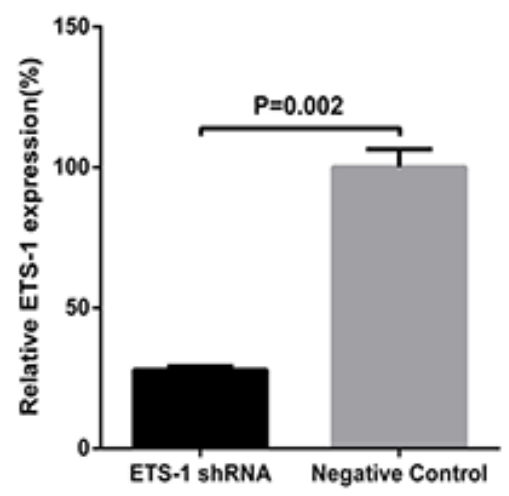

$E$

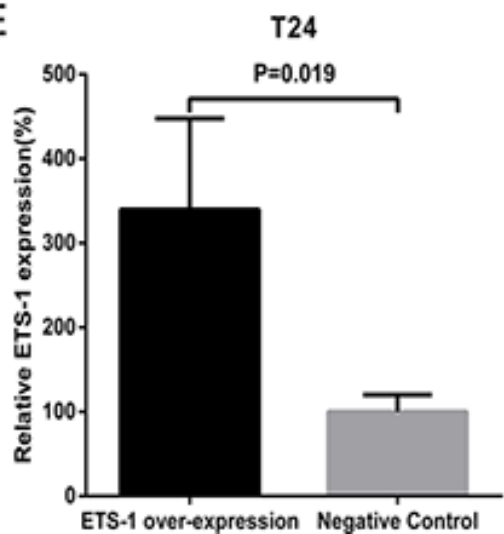

C

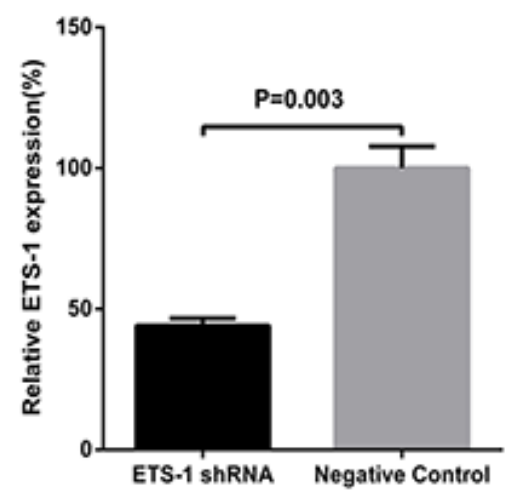

$\mathrm{F}$

UMUC-3

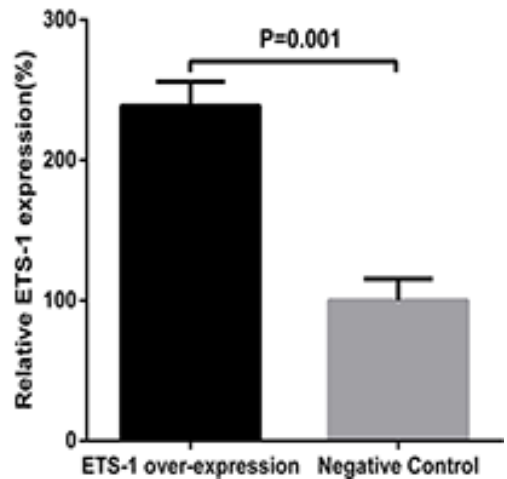

Figure 2: Inhibition or activation of the expression of ETS-1 in bladder cancer. The relative expression level was evaluated using real-time qPCR. Compared with negative control group, the ETS-1 specific shRNA obviously down-regulated the expression level of ETS-1 in 5637 cells (A) T24 cells (B) and UMUC-3 cells (C) Compared with negative control group, the ETS-1 over-expression vector obviously up-regulated the expression level of ETS-1 in 5637 cells (D) T24 cells (E) and UMUC-3 cells (F). Data are indicated as mean \pm S.D. 

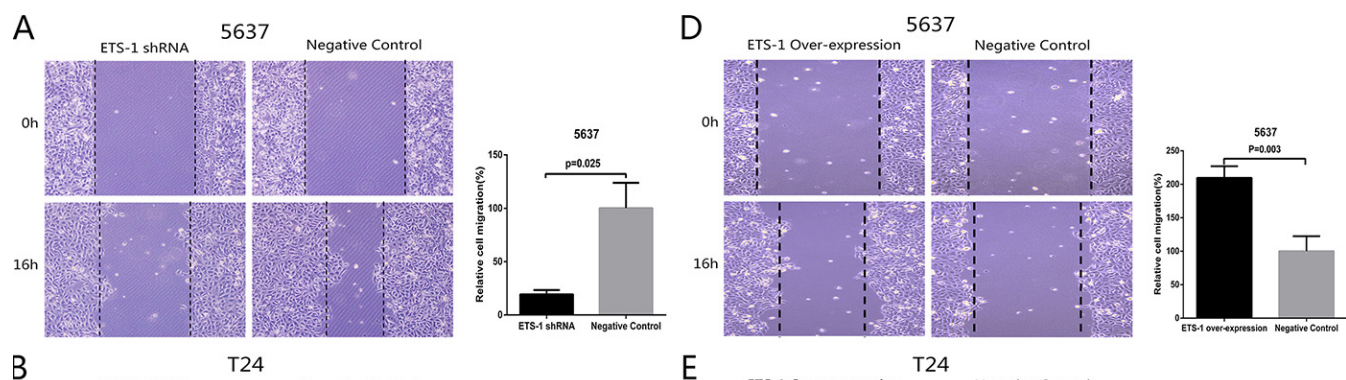

B
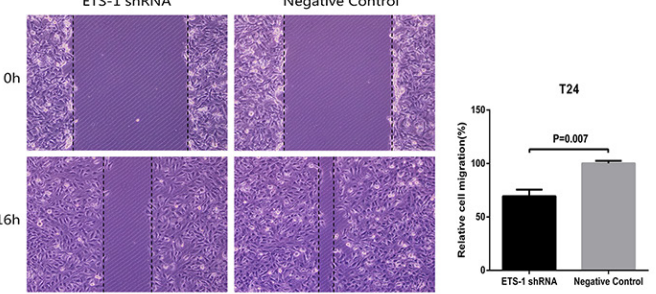

E

$\mathrm{T} 24$
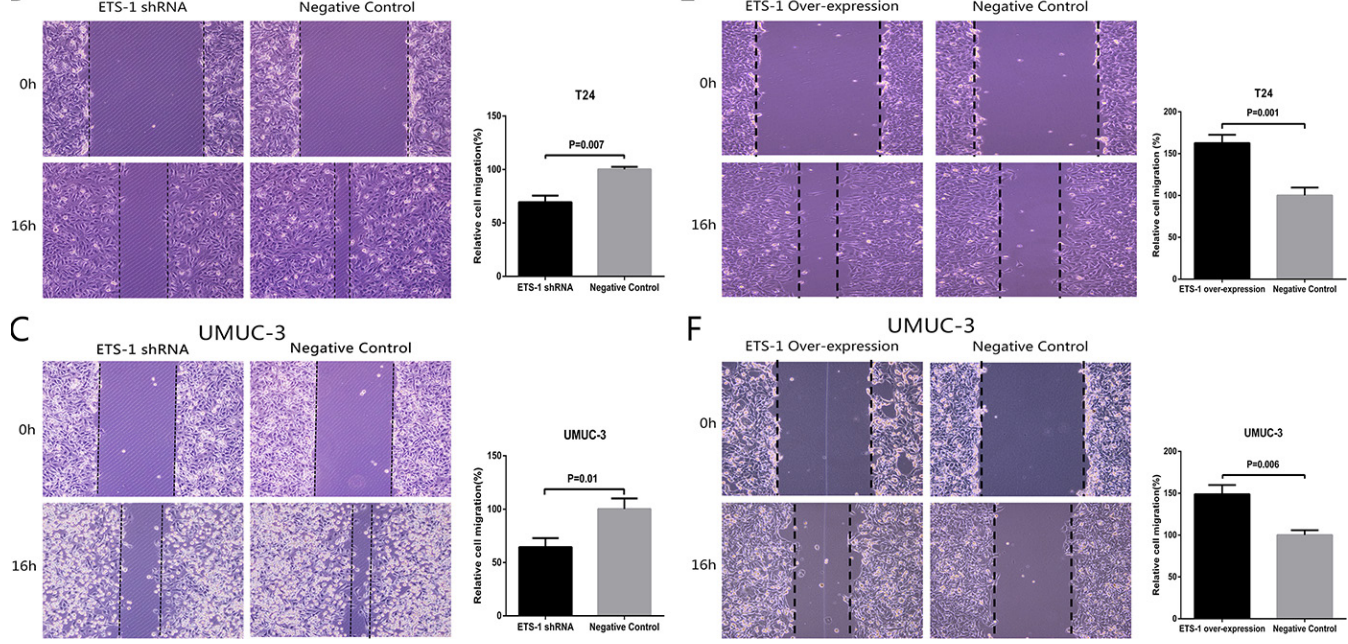

Figure 3: ETS-1 promoted bladder cancer cell migration in vitro. 5637 (A) T24 (B) and UMUC-3 cells (C) were treated with ETS-1 specific shRNA or negative control shRNA. 5637 (D) T24 (E) and UMUC-3 cells (F) were also transduced with ETS-1 overexpression vector or negative control and cell migration assay was performed as described in Material and Methods. Representational Figures of each experiment are shown. Data are presented as mean \pm SD. Each experiment in both cell lines was performed for three independent times.
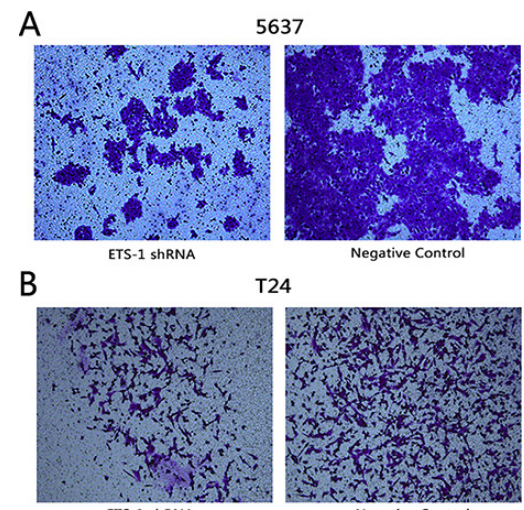

T24
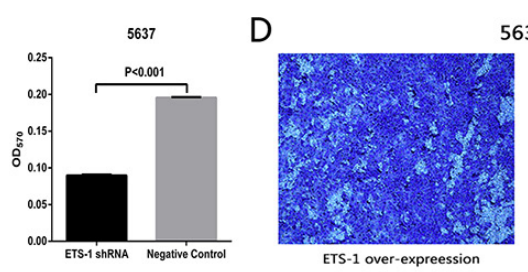

5637
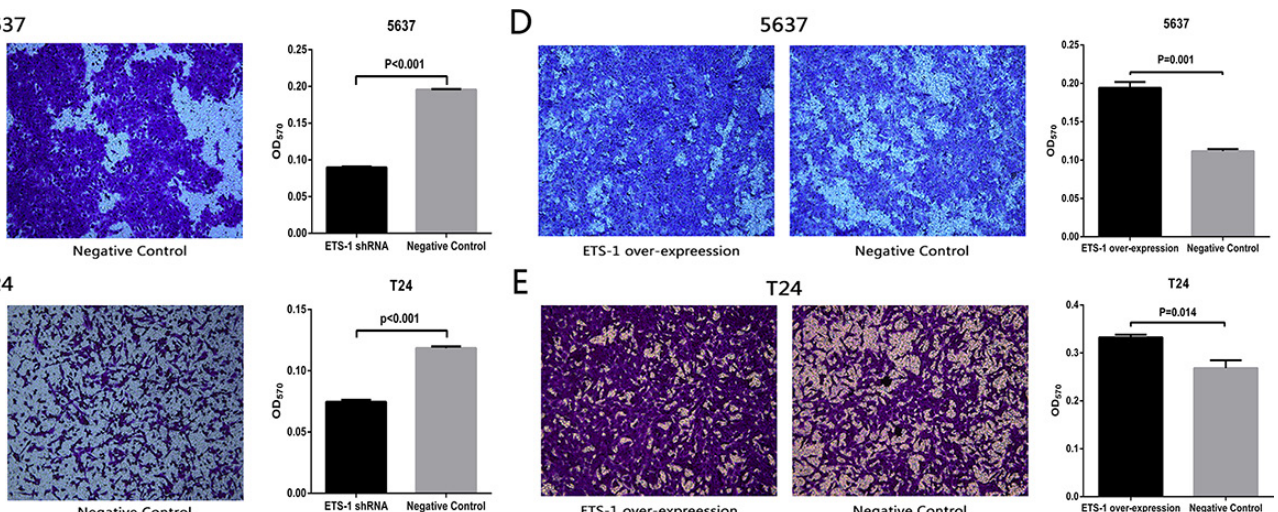

E
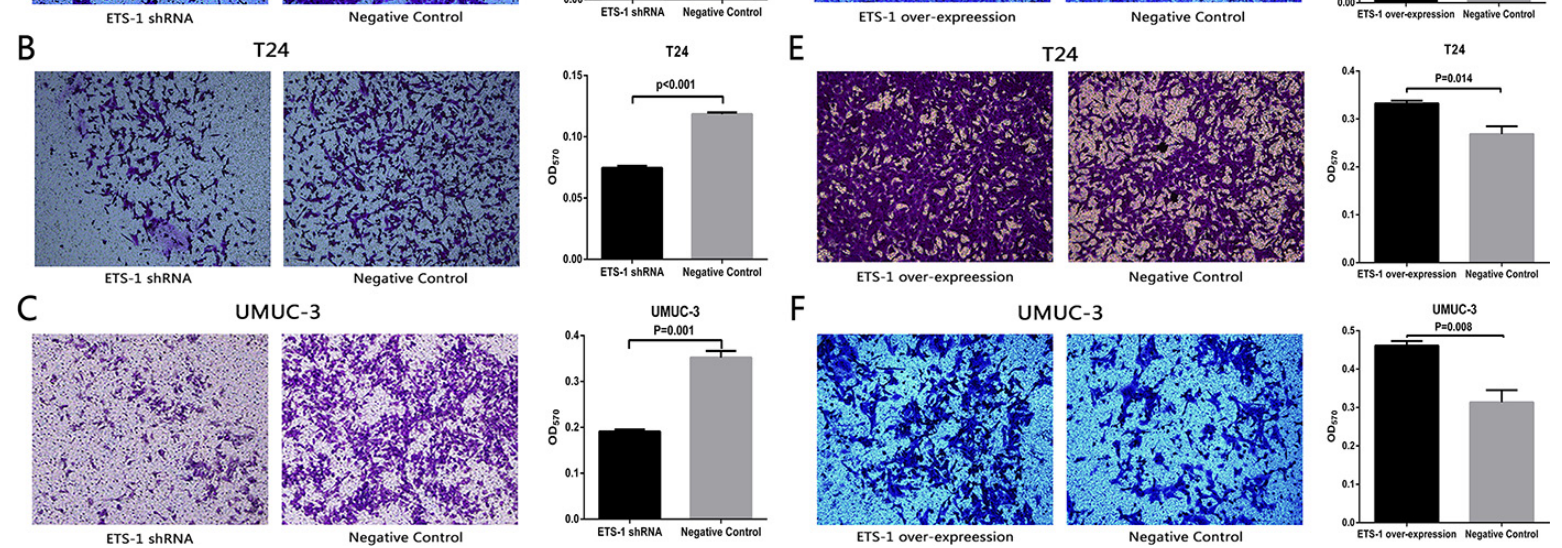

Negative Control

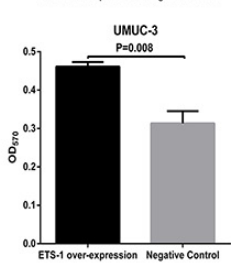

Figure 4: ETS-1 promoted bladder cancer cell invasion in vitro. Invasion ability of bladder cancer cell was detected by cell invasion assay, whose concrete operating procedures were shown in Material and Methods. Invaded cells were observed and imaged under the inverted microscope. Afterwards, the invaded cells within each chamber were soaked with $33 \%$ acetic acid to wash out the crystal violet, and then the absorbance of crystal violet was measured at the wavelength of $570 \mathrm{~nm}$ using microplate reader. Cell invasion inhibition was observed in bladder cancer 5637 cells (A) T24 cells (B) and UMUC-3 cells (C) treated with the shRNA. Cell invasion promotion was observed in bladder cancer 5637 cells (D) T24 cells (E) and UMUC-3 cells (F) treated with the over-expression vector. Representational Figures of each test are shown. Data are shown as mean \pm SD. Experiments were performed for three independent times. 
indicated that ETS-1 significantly promote cell invasion in bladder cancer.

\section{ETS-1 do not control cell proliferation in bladder cancer}

To explore whether ETS-1is associated with cell proliferation in bladder cancer, the bladder cancer cell lines treated with ETS-1 shRNA or over-expression vector were analyzed by the CCK- 8 assay and EdU assay. Both of the two results indicated that there was no difference in the proliferation rate between ETS-1 shRNA or over-expression vector group and negative control group in 5637 cells (Figure 5A, 5D, 5G and 5J), T24 cells (Figure 5B, 5E, 5H and $5 \mathrm{~K}$ ) and UMUC-3 cells (Figure 5C, 5F, 5I and 5L). These results confirmed that ETS-1 is not associated with the bladder cancer cell proliferation.

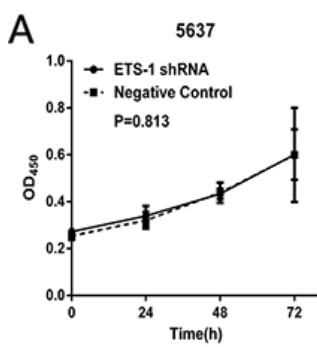

D

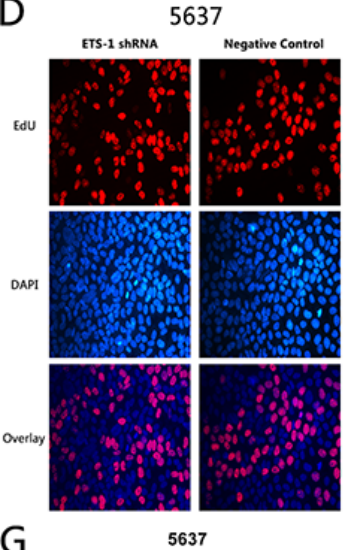

G

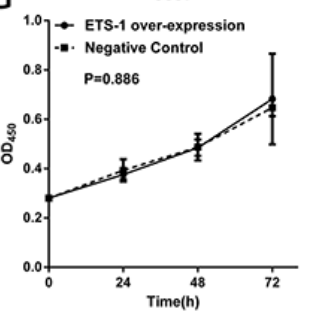

J
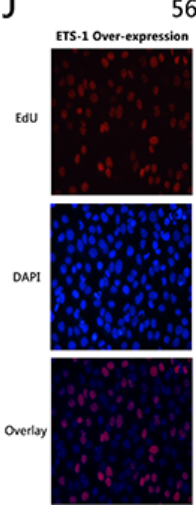

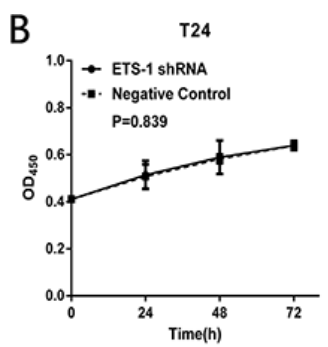

$\mathrm{E}$

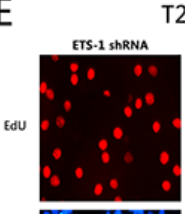

T24
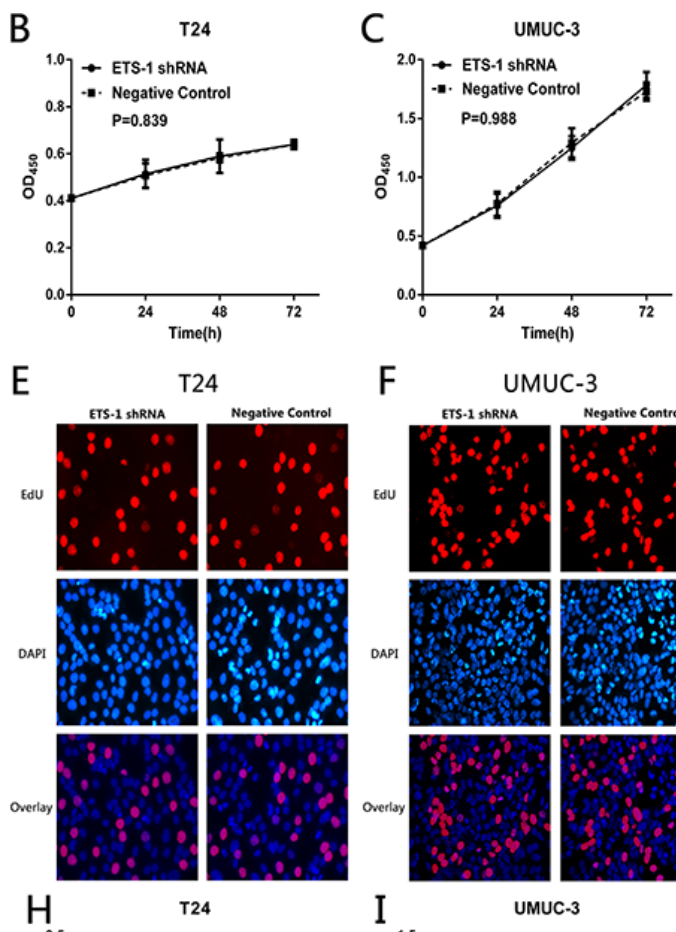

U UMUC-3

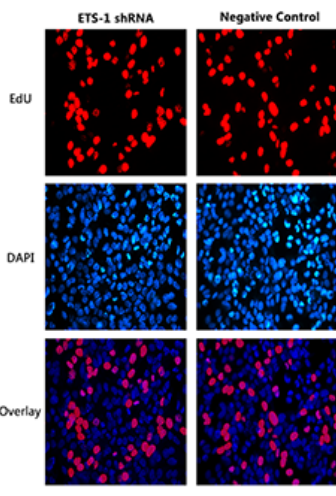

I

UMUC-3

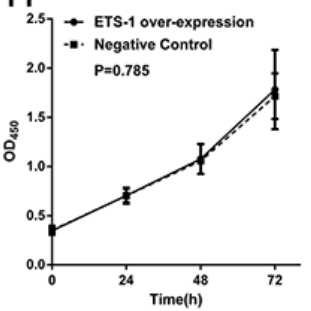

K

T24
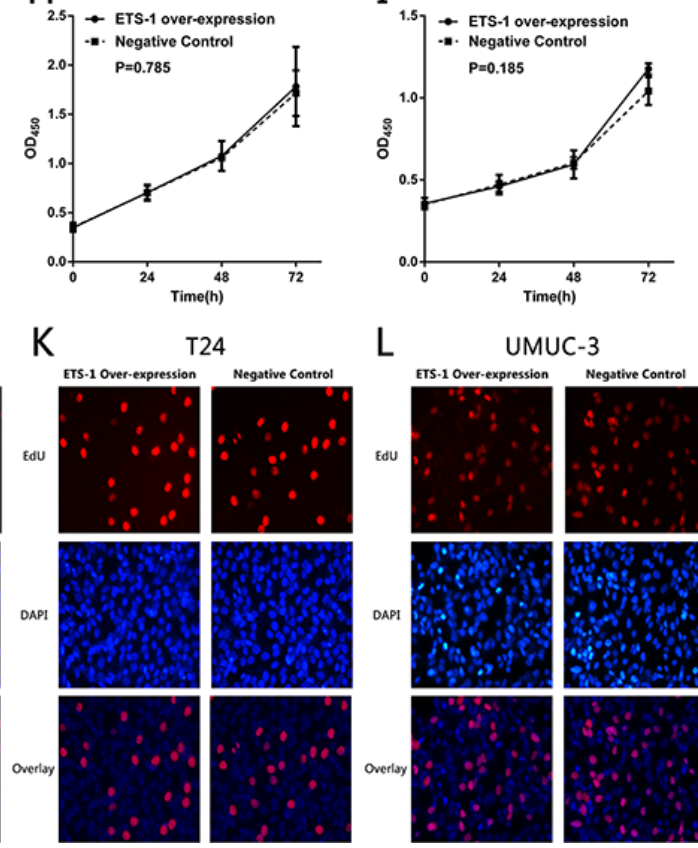

L UMUC-3
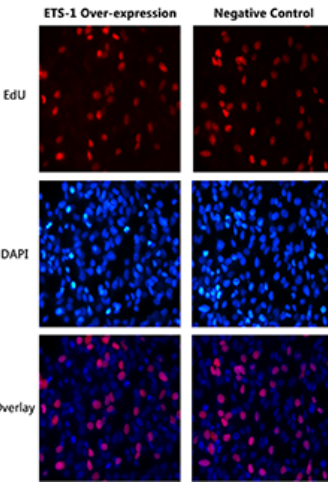

Figure 5: ETS-1 do not control cell proliferation in bladder cancer. Cell proliferation was measured by CCK-8 assay and EdU assay. There was no difference in cell proliferation rate between the treated group in bladder cancer 5637 cells $(\mathbf{A}, \mathbf{D}, \mathbf{G}, \mathbf{J})$,T24 cells $(\mathbf{B}, \mathbf{E}, \mathbf{H}, \mathbf{K})$ and UMUC-3 cells $(\mathbf{C}, \mathbf{F}, \mathbf{I}, \mathbf{L})$. The data are presented as mean \pm SD. Assays were repeated at least three times. 


\section{ETS-1 do not regulate cell apoptosis in bladder cancer}

Finally, we determined whether ETS-1 inhibit cell apoptosis in bladder cancer. At 48 hours after transfection of ETS-1 shRNA or transduction of the over-expression vector, the relative activity of caspase- 3 of the bladder cancer 5637 cells, T24 cells and UMUC-3 cells were detected by thecaspase-3 enzyme-linked immunosorbent assay (ELISA) assay. Regrettably, as shown in Figure $6 \mathrm{~A}-6 \mathrm{C}$, there was also no difference in the relative activity of caspase-3 between ETS-1 shRNA and negative control shRNA transfected group in these three bladder cancer cells. As shown in Figure 6C-6E, there was also no difference in the relative activity of caspase-3 between ETS-1over-expression vector and negative control transduced group in these three bladder cancer cells. The results indicated that ETS-1 has nothing to do with the bladder cancer cell apoptosis.

\section{DISCUSSION}

ETS-1, one of the ETS transcription factor members, is known to play important roles in a number of physiological and pathological processes, such as embryonic development, angiogenesis, and hematopoietic differentiation [3, 4]. For example, ETS1 is essential for Connective Tissue Growth Factor $(\mathrm{CTGF} / \mathrm{CCN} 2)$ induction mediated by TGF- $\beta 1$ in Osteoblasts [8] and ETS-1 is significant for EBNA3Cmediated up-regulation of AK-B transcription, which leads to degradation of p53 [9]. Furthermore, ETS-1 is expressed in many tumors and activates many cancer related genes that promote the malignant transformation and progression of tumors, including invasion, metastasis and neoangiogenesis [10-12]. In gastric tumors [13] and oral squamous cell carcinomas [14], the deregulation of ETS-1 was related with the invasive behavior and cancer metastasis. In addition, ETS-1was responsible for the malignant progression and invasion of meningiomas and human astrocytic tumor $[15,16]$. Over-expression of ETS-1was also reported in human breast cancer and angiosarcoma of the skin $[17,18]$.

In our study, we found that the expression level of ETS-1 was significantly up-regulated in bladder cancer tissues compared with matched normal tissues. These results in our research manifested that ETS-1 is likely to play oncogenic role in bladder cancer. To further understand the biological functions of ETS-1 in bladder cancer, the ETS-1 specific shRNA and over-expression vector were designed

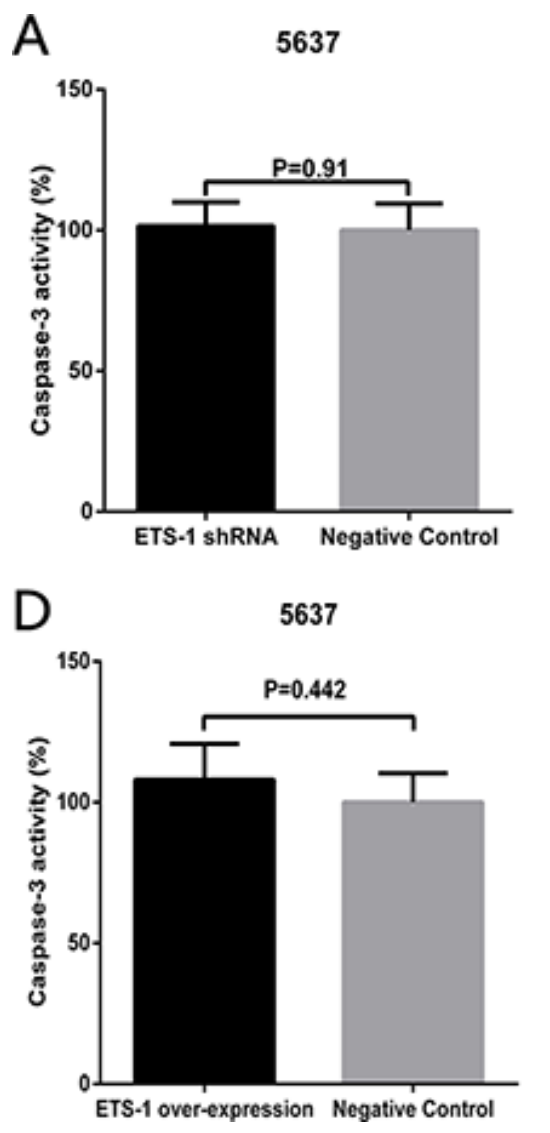

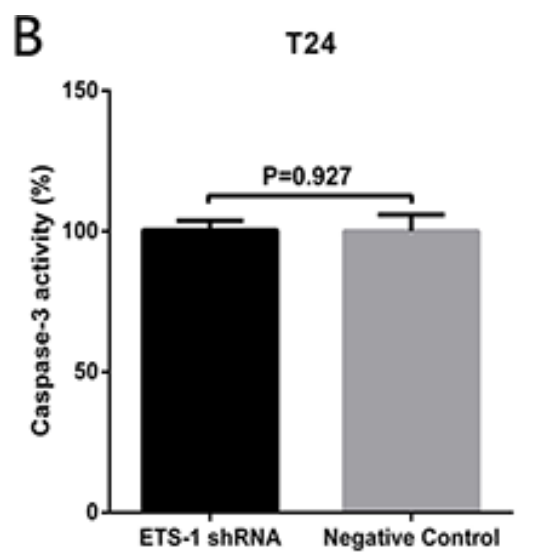

$\mathrm{E}$

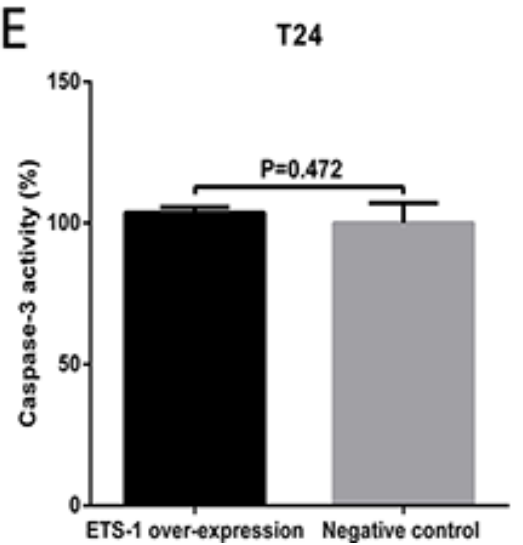

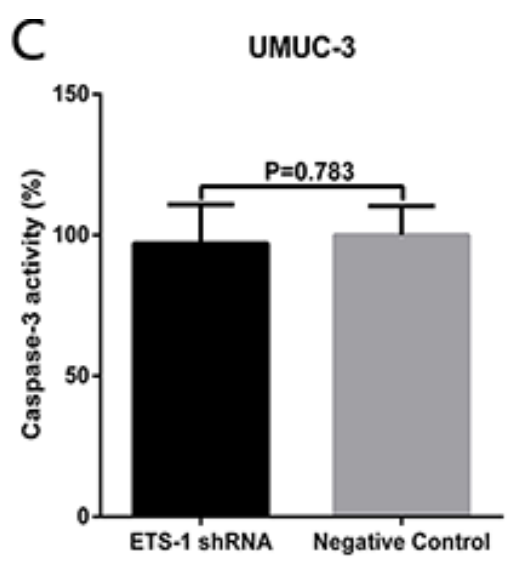

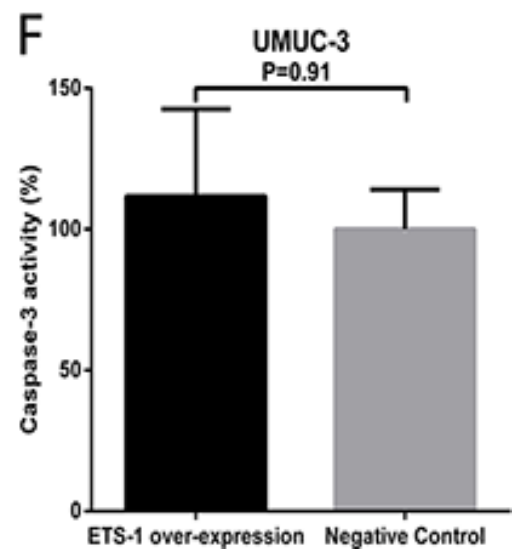

Figure 6: ETS-1 do not regulate cell apoptosis in bladder cancer. At 48 hours after treatment of ETS- 1 shRNA or overexpression vector, the cell apoptosis changes were determined by ELISA assay. There was no difference in the relative activity of caspase-3 in $5637(\mathbf{A}, \mathbf{D})$, T24 (B, E) and UMUC-3 cells $(\mathbf{C}, \mathbf{F})$. These results are presented as mean \pm SD. Tests were repeated at least three times. 
to treat bladder cancer cells, and then we used scratch assay and invasion assay to detect the cell migration ability and the cell invasiveness. As expected, ETS-1 promoted cell migration and cell invasion in the related bladder cancer cell lines. In addition, cell proliferation and cell apoptosis were tested by the CCK-8, EdU and ELISA assay to verify whether ETS-1 influences the cell proliferation and cell apoptosis in bladder cancer. Unfortunately, there were no differences in both the cell proliferation rate and the relative activity of caspase- 3 between the treated groups in bladder cancer cells. These findings indicate that ETS-1 may only play vital roles in the migration and invasion of bladder cancer, and did not affect the proliferation and apoptosis.

It should be noted that the results of the correlation of ETS-1 expression with the malignant phenotype of bladder cancer in our study is contrary to the findings from Aysegul S, et al. They reported that most of the low-grade and noninvasive bladder cancer largely expressed ETS-1, and that high-grade and invasive bladder cancer showed a frequent decrease or loss of ETS-1expression [19]. But they only used immunohistochemical staining to investigate the expression of ETS-1 and did not perform the functional experiments in their studies. The expression of ETS-1 was not associated with grade of bladder cancer $(P=0.202)$ (Table 2) in our study. More clinic samples should be needed to reveal the correlation of ETS-1 expression pattern with the clinical-pathological characteristics in bladder cancer.

In conclusion, the results of this research demonstrate that ETS-1 is highly expressed in the bladder cancer compared to matched normal bladder tissue, and promotes bladder cancer cell migration and invasion. Hence, ETS-1 should play oncogenic roles in human bladder cancer and it can be used as a therapeutic target for treating human bladder cancer. The future works are still needed to study the molecular mechanisms of ETS-1 which maybe a candidate biomarker for bladder cancer in the clinic.

\section{MATERIALS AND METHODS}

\section{Patient samples}

42 patients with bladder urothelial carcinomas were included in the study. Bladder cancer tissue and paired normal bladder tissue from each patient were snap-frozen in liquid nitrogen instantly after partial or radical cystectomy. Written informed consents were obtained from all the patients. The clinical-pathological characteristics of the patients are summarized in Table 2. The study was approved by the Institutional Review Board of Shenzhen Second People's Hospital.

\section{Cell lines and culture conditions}

Bladder cancer T24, 5637 and UMUC-3 cells were purchased from the Institute of Cell Biology, Chinese
Academy of Sciences (Shanghai, China). T24 cell line and UMUC-3 cell line were cultured in Dulbecco's Modified Eagle Medium (Gibco, Grand Island, NY, USA) supplemented with $10 \%(\mathrm{v} / \mathrm{v})$ fetal bovine serum (Gibco, Grand Island, NY, USA) at $37^{\circ} \mathrm{C}$ in a $5 \% \mathrm{CO}_{2}$ atmosphere. 5637 cell line was cultured in RPMI-1640 Medium (Gibco, Grand Island, NY, USA) supplemented with $10 \%(\mathrm{v} / \mathrm{v})$ fetal bovine serum (Gibco, Grand Island, $\mathrm{NY}, \mathrm{USA}$ ) at $37^{\circ} \mathrm{C}$ in a $5 \% \mathrm{CO}_{2}$ atmosphere.

\section{Construction of ETS-1 shRNA vector and cell transfection}

Either the small-hairpin RNA (shRNA) targeting ETS-1 or the negative control shRNA targeting no known sequence were cloned into the $\mathrm{pGPU} / \mathrm{GFP} / \mathrm{Neo}$ vector (GenePharma, Shanghai, China). The ETS-1 shRNA sequence was 5'-CTGATGTAAGGCAATTAAT-3' [20]. The bladder cells lines were incubated with either ETS-1 shRNA or negative control shRNA using LipoFiter ${ }^{\mathrm{TM}}$ Liposomal Transfection Reagent (Hanbio, Shanghai, China) according to the protocol.

\section{Construction of lentivirus-mediated ETS-1over- expression vector and cell transduction}

Human ETS-1 cDNA (NM_001143820) was amplified, purified, and inserted into a lentiviral vector encoding enhanced GFP $[21,22]$. The recombinant lentiviral vector expressing ETS-1 (ETS-1 overexpression vector) and the empty vector (Negative control) were constructed from Genechem Co., Ltd (Shanghai, China). The packaging, purification, and titer determination of the recombinant lentiviruses were carried out in HEK293T cells as previously described $[23,24]$. Finally, the titers of the recombinant lentiviruses were $2 \times 10^{8}$ and $1 \times 10^{9}$ infectious units $/ \mathrm{mL}$, respectively.

Bladder cancer cells were cultured in 6-well plates $\left(2 \times 10^{5} /\right.$ well $)$ and infected with the lentivirus at a multiplicity of infection (MOI) of 20 for $24 \mathrm{~h}$. Cells were selected using puromycin (Sigma-Aldrich, St. Louis, MO, USA) for getting stable ETS-1 expression. At last, ETS-1 expression in the infected cells was confirmed by means of qRT-PCR.

\section{Total RNA extraction and reverse transcription}

Total RNA was extracted from the tissue samples, the transfected cells and the infected cells by using TRIzol $^{\mathrm{TM}}$ reagent (Invitrogen, Carlsbad, CA, USA) according to the manufacturer's instructions. cDNA was converted from total RNA by using the PrimeScript ${ }^{\mathrm{TM}} \mathrm{RT}$ reagent Kit with gDNA Eraser (TaKaRa, Otsu, Shiga, Japan) according to the instructions. 
Table 2: Summary of clinical-pathological features of bladder cancer patients

\begin{tabular}{|c|c|c|c|c|c|c|c|c|c|}
\hline No. & Sex & Age & Grade & Stage & No. & Sex & Age & Grade & Stage \\
\hline 1 & $\mathrm{M}$ & 59 & Low & T2bN0M0 & 22 & M & 70 & Low & TaN0M0 \\
\hline 2 & $\mathrm{~F}$ & 74 & High & T3aN0M0 & 23 & M & 68 & Low & T2bN0M0 \\
\hline 3 & M & 69 & High & T2bN0M0 & 24 & M & 57 & High & T3aN0M0 \\
\hline 4 & M & 66 & High & T2bN0M0 & 25 & $\mathrm{~F}$ & 41 & Low & T2aN0M0 \\
\hline 5 & M & 62 & High & T4aN0M0 & 26 & M & 73 & High & T2bN0M0 \\
\hline 6 & M & 71 & High & T2bN0M0 & 27 & M & 66 & High & T3aN2M0 \\
\hline 7 & M & 65 & High & T2bN0M0 & 28 & M & 72 & Low & T1N0M0 \\
\hline 8 & M & 58 & High & T4aN3M0 & 29 & $\mathrm{~F}$ & 62 & Low & T4N0M0 \\
\hline 9 & M & 57 & High & T4aN0M0 & 30 & $\mathrm{~F}$ & 73 & High & T2aN0M0 \\
\hline 10 & M & 64 & High & T3aN0M0 & 31 & M & 74 & High & T2bN0M0 \\
\hline 11 & M & 75 & High & T2bN0M0 & 32 & M & 67 & Low & T1N0M0 \\
\hline 12 & M & 58 & High & T4aN0M0 & 33 & $\mathrm{~F}$ & 75 & High & T1N0M0 \\
\hline 13 & $\mathrm{M}$ & 63 & High & T3aN0M0 & 34 & M & 72 & High & T3aN1M0 \\
\hline 14 & $\mathrm{M}$ & 63 & High & T2bN0M0 & 35 & M & 78 & High & T2aN0M0 \\
\hline 15 & M & 66 & High & T2bN0M0 & 36 & M & 53 & Low & T1N0M0 \\
\hline 16 & M & 48 & Low & T1N0M0 & 37 & $\mathrm{~F}$ & 61 & High & T3aN0M0 \\
\hline 17 & $\mathrm{M}$ & 53 & High & T1N1M0 & 38 & $\mathrm{~F}$ & 81 & Low & T1N0M0 \\
\hline 18 & $\mathrm{M}$ & 66 & High & T1N0M0 & 39 & M & 56 & High & T4aN0M0 \\
\hline 19 & $\mathrm{M}$ & 65 & High & T3aN0M0 & 40 & $\mathrm{M}$ & 49 & Low & T1N0M0 \\
\hline 20 & $\mathrm{~F}$ & 79 & High & T4aN0M0 & 41 & $\mathrm{M}$ & 55 & High & T1N0M0 \\
\hline 21 & $\mathrm{~F}$ & 64 & High & T2aN0M0 & 42 & M & 65 & High & T1N0M0 \\
\hline
\end{tabular}

No., patient number. M, male. F, female. Age, years old. Grade, the 2004 World Health Organization classification. Stage, American Joint Committee on Cancer TNM classification.

\section{Real-time quantitative polymerase chain reaction (qRT-PCR)}

qRT-PCR analyses were conducted with SYBR Premix Ex Taq ${ }^{\text {TMII }}$ (TaKaRa, Otsu, Shiga, Japan). The primer sequences were as follows: ETS-1 primers [25] forward: 5'-TCATTTCTTTGCTGCTTGGA-3', reverse: 5'- AAGCCGACTCTCACCATCAT-3'; $\beta$-actin primers [26] forward: 5'- GCGAGAAGATGACCCAGAT-3', reverse: 5'- GAGGCGTACAGGGATAGC-3'. qPCR was performed in a total reaction volume of $20 \mu$, including $2 \mu \mathrm{l}$ of First-Strand cDNA, $0.8 \mu \mathrm{l}$ of forward primer, $0.8 \mu \mathrm{l}$ of reverse primer, $10 \mu \mathrm{l}$ of $2 \times$ SYBR Premix Ex Taq ${ }^{\mathrm{TM} I I}$, $0.4 \mu \mathrm{l}$ of $50 \times$ ROX Reference Dye II and $6 \mu$ of doubledistilled water. The reactions were performed in triplicate by using the ABI PRISM 7000 Fluorescent Quantitative
PCR System (Applied Biosystems, Foster City, CA, USA). $\beta$-actin was chosen as the internal control. The average value in each triplicate was used to calculate the relative amount of ETS- 1 using the $2^{-\Delta \Delta C t}$ methods.

\section{Cell migration assay}

The treated cells were seeded on the 6-well plates $\left(5 \times 10^{5} /\right.$ well). At about $90 \%$ confluent cells, a clean line was created by using a sterile $200 \mu \mathrm{l}$ pipette tip at $5 \mathrm{~h}$ post transfection. The migration of cells was monitored using a digital camera system and imaged at the time of $0 \mathrm{~h}$ and $16 \mathrm{~h}$. The cell migration distance $(\mathrm{mm})$ was calculated using the software program HMIAS-2000. Experiments were performed at least three times. 


\section{Cell invasion assay}

About $1 \times 10^{5}$ treated cells with $100 \mu$ serum-free medium were plated into the upper chambers (24-well insert, pore size $8 \mu \mathrm{m}$, Corning) which were added with Matrigel (1:8, $50 \mu \mathrm{l} /$ well, BD Bioscience, San Jose, CA, USA) . Concurrently, the lower chambers were filled with $500 \mu \mathrm{l}$ medium containing $10 \%$ fetal bovine serum. Cells were cultured at $37^{\circ} \mathrm{C}$ in a $5 \% \mathrm{CO}_{2}$ atmosphere for 48 hours. Cells under the surface of the lower chamber were washed with $1 \times$ PBS, fixed with $4 \%$ paraformaldehyde for $20 \mathrm{~min}$, stained with $0.1 \%$ crystal violet for $25 \mathrm{~min}$, and then washed 3 times. Invaded cells were observed under the inverted microscope and imaged. Afterwards, each chamber with the invaded cells was soaked into $1 \mathrm{ml} \mathrm{33 \%}$ acetic acid for $10 \mathrm{~min}$ to wash out the crystal violet. $100 \mu \mathrm{l} /$ well $33 \%$ acetic acid were added into 96-well plates, and the absorbance was measured at a wavelength of $570 \mathrm{~nm}$ using a microplate reader (Bio-Rad, Hercules, CA, USA). Experiments were performed in triplicate.

\section{Cell proliferation assay}

The effects of down-regulation or up-regulation ETS-1 on cell proliferation were examined by Cell Counting Kit-8 (CCK-8) (Beyotime, Shanghai, China) according to the previous studies $[27,28]$. The treated cells were seeded in a 96-well plate $\left(5 \times 10^{3} /\right.$ well $)$ and cultured in normal medium. At $0,24,48$, and $72 \mathrm{~h}$ after transfection, $15 \mu 1$ of CCK- 8 was added into each well of 96-well plate and the cells were cultured for 1 hour. Absorbance was measured at a wavelength of $450 \mathrm{~nm}$ using a microplate reader (Bio-Rad, Hercules, CA, USA). Assays were repeated at least three times.

Cell proliferation was also tested by 5- ethynyl2-deoxyuridine (EdU) incorporation assay using the corresponding kit (Ribobio, Guangzhou, China) .The EdU incorporation assay was carried out according to the previous studies $[29,30]$. Finally, the cells were observed using fluorescence microscopy. All experiments were performed in three times.

\section{Cell apoptosis assay}

The effects of down-regulation or up-regulation ETS-1 on cell apoptosis were detected by calculating the activity of caspase- 3 using the Caspase- 3 enzyme-linked immunosorbent assay (ELISA) assay kit (Hcusabio, Wuhan, China) according to the manufacturer's instructions. Absorbance was measured by using a microplate reader (Bio-Rad, Hercules, CA, USA). Data were shown as the ratios between the absorbance of experimental groups and those of negative control groups. Each test was carried out at least three times.

\section{Statistical analyses}

All experimental data from three independent experiments were presented as mean \pm standard deviation (SD). All statistical data were analyzed by SPSS 19.0 software (SPSS Inc.Chicago, IL, USA). The ETS-1 RNA expression differences between bladder cancer tissue and matched normal tissue were analyzed using paired samples $t$-test. The relationship between ETS-1 level and clinicalpathologic characteristics in 42 patients with bladder cancer were analyzed by Continuous correction chi-square test. The data of CCK- 8 assay were analyzed by ANOVA and independent samples $t$-test was used to analyze other data. A $P$ value of less than 0.05 was considered to be statistically significant.

\section{ACKNOWLEDGMENTS AND FUNDING}

The authors are appreciative to the donors, whose names were not included in the author list, but who participated in this program. This work was funded by the National Key Basic Research Program of China (973 Program) (2014CB745201), the Chinese High-Tech (863) Program (2014AA020607), National Natural Science Foundation of China [81402103], International S \& T Cooperation program of China (ISTCP) (2014DFA31050), The National Science Foundation Projects of Guangdong Province (2014A030313717), the Shenzhen Municipal Government of China (ZDSYS201504301722174, JCYJ20150330102720130, GJHZ20150316154912494), and Special Support Funds of Shenzhen for Introduced High-Level Medical Team.

\section{CONFLICTS OF INTEREST}

There is no conflicts of interest between the authors.

\section{REFERENCES}

1. Parkin DM, Bray F, Ferlay J, Pisani P. Global cancer statistics, 2002. CA Cancer J Clin. 2005; 55:74-108.

2. Kim WJ, Bae SC. Molecular biomarkers in urothelial bladder cancer. Cancer Sci. 2008; 99:646-652.

3. Maroulakou IG, Bowe DB. Expression and function of Ets transcription factors in mammalian development: a regulatory network. Oncogene.2000; 19:6432-6442.

4. Sato, Y. Role of ETS family transcription factors in vascular development and angiogenesis. Cell Struct Funct. 2001; 26:19-24.

5. Keehn CA, Smoller BR, Morgan MB. Expression of the ets-1 protooncogene in melanocytic lesions. Mod Pathol. 2003; 16:772-777. 
6. Nakayama T, Ito M, Ohtsuru A, Naito S, Sekine I. Expression of the ets-1protooncogene in human colorectal carcinoma. Mod Pathol. 2001; 14:415-422.

7. Saeki H, Kuwano H, Kawaguchi H, Ohno S, Suqimachi K. Expression of ets-1transcription factor is correlated with penetrating tumor progressionin patients with squamous cell carcinoma of the esophagus. Cancer.2000; 89:1670-1676.

8. Geisinger MT, Astaiza R, Butler T, Popoff SN, Planey SL, Arnott JA. Ets-1 is essential for Connective Tissue Growth Factor(CTGF/CCN2) induction by TGF- $\beta 1$ in Osteoblasts. PLoS One. 2012; 7: e35258.

9. Jha HC, Yang K, El-Naccache DW, Sun Z, Robertson ES. EBNA3C regulates p53 through induction of Aurora kinase B. Oncotarget. 2015; 6:5788-5803. doi: 10.18632/ oncotarget.3310.

10. Hahne JC, Okuducu AF, Sahin A, Fafeur V, Kiriakidis S, Wernert N. The transcription factor ETS-1: its role in tumour development and strategies for its inhibition. Mini Rev Med Chem. 2008;8: 1095-1105,

11. Dittmer J. The biology of the Ets1 proto-oncogene. Mol Cancer. 2003; 2:29.

12. Li D, Bi FF, Cao JM, Cao C, Li CY, Liu B, Yang Q. Poly (ADP-ribose) polymerase 1 transcriptional regulation: a novel crosstalk between histone modification $\mathrm{H} 3 \mathrm{~K} 9 \mathrm{ac}$ and ETS1 motif hypomethylation in BRCA1-mutated ovarian cancer. Oncotarget. 2014; 5:291-297. doi: 10.18632/ oncotarget. 1549.

13. Yu Y, Zhang YC, Zhang WZ, Shen LS, Hertzog P, Wilson TJ, $\mathrm{Xu}$ DK. Ets1 as a marker of malignant potential in gastric carcinoma. World J Gastroenterol. 2003,9:2154-2159.

14. Pande P, Mathur M, Shukla NK, Ralhan R. Ets-1: a plausible marker of invasive potential and lymph node metastasis in human oralsquamous cell carcinomas. J Pathol. 1999;189:40-45.

15. Kitange G, Tsunoda K, Anda T, Nakamura S, Yasunaga A, Naito S, Shibata S. Immunohistochemical expression of Ets1 transcription factor and the urokinase-type plasminogen activator is correlated with the malignant and invasive potential in meningiomas. Cancer. 2000; 89:2292-2300.

16. Kitange G, Kishikawa M, Nakayama T, Naito S, Iseki M, Shibata S. Expression of the Ets-1 proto-oncogene correlates with malignant potential in human astrocytic tumors. Mod Pathol. 1999; 12:618-626.

17. Buggy Y, Maguire TM, McGreal G, McDermott E, Hill AD, O'Higgins N, Duffy MJ. Overexpression of the Ets-1 transcription factor in human breast cancer. $\mathrm{Br} J$ Cancer.2004; 91:1308-1315.

18. Naito S, Shimizu K, Nakashima M, Nakayama T, Ito T, Ito M, Yamashita S, Sekine I. Overexpression of Ets1 transcription factor in angiosarcoma of the skin. Pathol Res Pract.2000; 196:103-109.

19. Sari A, Calli A, Gorgel SN, Altinboga AA, Kara C, Dincel C, Cakalagaoglu F. Immunohistochemical determination of ETS-1oncoprotein expression in urothelial carcinomas of the urinary bladder. Appl Immunohistochem Mol Morphol. 2012; 20:153-158.

20. Hollenhorst PC, Chandler KJ, Poulsen RL, Johnson WE, Speck NA, Graves BJ. DNA Specificity Determinants Associate with Distinct Transcription Factor Functions. PLoS Genet. 2009; 5:e1000778.

21. Follenzi A, Naldini L. HIV-based vectors, preparation and use. Methods Mol Med. 2002; 69:259-274.

22. Blits B, Kitay BM, Farahvar A, Caperton CV, Dietrich WD, Bunge MB. Lentiviral vector-mediated transduction of neural progenitor cells before implantation into injured spinal cord and brain to detect their migration, deliver neurotrophic factors and repair tissue. Restor Neurol Neurosci. 2005; 23:313-324.

23. Follenzi A, Naldini L. Generation of HIV-1 derived lentiviral vectors. Methods Enzymol. 2002; 346:454-465.

24. Rubinson DA, Dillon CP, Kwiatkowski AV, Sievers C, Yang L, Kopinja J, Rooney DL, Zhang M, Ihrig MM, McManus MT, Gertler FB, Scott ML, Van Parijs L. A lentivirus-based system to functionally silence genes in primary mammalian cells, stem cells and transgenic mice by RNA interference. Nat Genet. 2003; 33:401-406.

25. Smith AM, Findlay VJ, Bandurraga SG, Kistner-Griffin E, Spruill LS, Liu A, Golshayan AR, Turner DP. ETS-1 transcriptional activity is increased in advanced prostate cancer and promotes the castrate-resistant phenotype. Carcinogenesis. 2012; 33:572-580.

26. Golestani Eimani B, Sanati MH, Houshmand M, Ataei M, Akbarian F, Shakhssalim N. Expression and prognostic significance of Bcl-2 and Bax in the progression and clinical outcome of transitional bladder cell carcinoma. Cell J. 2014; 15:356-363.

27. Li H, Yu B, Li J, Su L, Yan M, Zhu Z, Liu B. Overexpression of lncRNA H19 enhances carcinogenesis and metastasis of gastric cancer. Oncotarget. 2014; 5:2318-2329. doi: 10.18632/oncotarget.1913.

28. Liu L, Liu Y, Zhuang C, Xu W, Fu X, Lv Z, Wu H, Mou L, Zhao G, Cai Z, Huang W. Inducing cell growth arrest and apoptosis by silencing long non-coding RNA PCAT-1 in human bladder cancer. Tumour Biol. 2015; 36:7685-7689.

29. Zhan Y, Liu Y, Lin J, Fu X, Zhuang C, Liu L, Xu W, Li J, Chen M, Zhao G, Huang W, Cai Z. Synthetic Tet-inducible artificial microRNAs targeting $\beta$-catenin or HIF- $1 \alpha$ inhibit malignant phenotypes of bladder cancer cells T24 and 5637. Sci Rep. 2015; 5:16177.

30. Zhuang C, Li J, Liu Y, Chen M, Yuan J, Fu X, Zhan Y, Liu L, Lin J, Zhou Q, Xu W, Zhao G, Cai Z, et al. Tetracyclineinducible shRNA targeting long non-coding RNA PVT1 inhibits cell growth and induces apoptosis in bladder cancer cells. Oncotarget. 2015; 6:41194-41203. doi: 10.18632/ oncotarget.5880. 